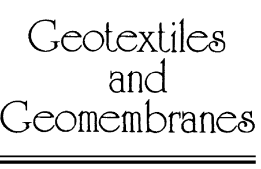

Geotextiles and Geomembranes 18 (2000) 251-261

www/elsevier.com/locate/geotexmem

Technical Note

\title{
Measurement of air permeability of geosynthetic clay liners
}

\author{
Hsin-Yu Shan*, Jenn-Tien Yao
}

Department of Civil Engineering, National Chiao Tung University, 1001 Ta Hsueh Road, Taiwan

Received 25 November 1998; received in revised form 15 July 1999; accepted 17 August 1999

\begin{abstract}
Hydraulic barrier layer is the major component in the cover system of a modern landfill. The primary function of the barrier is to limit the amount of water infiltration. Another important function is to minimize the emission of landfill gas. In recent years, geosynthetic clay liners (GCLs) have been used in landfill covers as hydraulic barrier layer. However, in hot and arid areas the bentonite in GCLs may develop desiccation cracks. Before the cracks are closed upon wetting, significant amount of landfill gas might have already emitted into the atmosphere. To address this issue, air permeability tests were performed to assess the effectiveness of GCLs as a gas barrier. The results show that air can hardly pass through hydrated GCL specimens. However, the drying of GCLs induced significant increase of their air permeability. (C) 2000 Elsevier Science Ltd. All rights reserved.
\end{abstract}

Keywords: Geosynthetic clay liner; Air permeability; Landfill gas; Desiccation; Landfill cover

\section{Introduction}

In recent years, GCLs have often been used as substitutes for the compacted soil components of the landfill cover systems. The major advantages of GCLs are the more consistent physical properties, the lower leakage rates, the faster installation, and the reduced construction quality assurance (CQA) requirements. These features make GCLs very attractive hydraulic barrier materials. Although they are often recommended to be used with geomembranes as composite liners (Koerner and Daniel, 1997),

\footnotetext{
* Corresponding author. Tel.: 00886-3-571-2121; fax: 00886-571-6257.

E-mail address: hyshan@cc.nctu.edu.tw (H.-Y. Shan)
} 
the GCLs have been used as the sole hydraulic barrier layer in many cases (Daniel and Scranton, 1996). The unique features of GCLs such as the ability to withstand differential settlement and the ability to self-heal desiccation cracks make them especially suitable for use in landfill covers.

The hydraulic properties of GCLs have been extensively studied since the beginning of 1990s as the demand for technical information on these products increased. Due to the favorable results of these studies and successful field experiences, the use of GCLs has grown rapidly. However, in municipal solid waste (MSW) landfills that generate significant amounts of gas, a hydraulic barrier layer must also be capable of limiting the flow of the up-moving gas as well as the infiltrating water. As a result, it is necessary to evaluate the effectiveness of the GCL as gas barrier.

The objective of this study was to develop the equipment for measuring the air permeability of GCLs and to investigate the variation of air permeability with the water content of the bentonite.

\section{Gas permeability and water retention of GCLs in landfill cover}

Considerable amount of gas is generated in municipal solid waste (MSW) landfills as the organic waste decomposes. The major portion of the gas is methane produced by anaerobic degradation, which lasts for more than thirty years.

It seems almost impossible for incidents such as explosions to happen in a properly designed and operated landfill. However, it is not the case in the real world. For instance, there are explosions and fires at operating and closed landfills in Taiwan every summer. In the southern part of Taiwan the weather is hot and arid. The average temperature can be as high as $30^{\circ} \mathrm{C}$ from May to October. The compacted soils of the daily covers or final covers are likely to be desiccated by the heat in such an environment and may not be able to contain methane gas. Once the methane gas moves upwards and mixes with oxygen in the air, even the sunlight that passes through a water-filled glass bottle can set up a fire.

Although it is an important issue, very little information is available regarding the gas emission of landfills. Figueroa and Stegmann (1991) performed several field tests on a $0.6 \mathrm{~m}$-thick soil cover at a German landfill. They found that the landfill gas flow rates ranged from $5.2 \times 10^{-6}$ to $9.6 \times 10^{-5} \mathrm{~m}^{3} / \mathrm{m}^{2} / \mathrm{s}$. They also recognized that if cracks formed in the soil liner due to desiccation or differential settlement, the flow rate could increase significantly. In addition, they suggested that the dominant gas transport mechanism was advection.

Theoretically, wet compacted soils as well as hydrated GCLs would hardly allow any gas to pass through (Daniel, 1991). As a result, GCLs' gas permeability has seldom been studied. Nevertheless, Trauger and Lucas (1995) did measure the rate of methane gas migrating through GCLs via diffusion. Their results show that the rate of gas transport through GCL was very low as long as its water content was greater than $90 \%$. The permeance is about $2 \times 10^{-6} \mathrm{~m} / \mathrm{s}$ for GCL sample with a water content of around $50 \%$ and drops below $1 \times 10^{-9} \mathrm{~m} / \mathrm{s}$ when water content reached above $90 \%$. This suggests that the gas permeability of GCLs is dependent on the water content. 
The GCLs' capability to absorb water from the surrounding soils is supported by the results of several studies. For example, Daniel et al. (1993) described the water absorption tests where dry GCL specimens were buried in sands of various water contents. They found that the bentonite did absorb considerable amount of water from the surrounding sand over the 40-days test period. However, their results showed that the final water content of bentonite in the GCL specimens placed in drier sands were much lower than that of fully saturated GCLs.

On the other hand, the ability of hydrated GCLs to retain water has also been investigated (Geoservices, 1989). The tests were performed in an environmental chamber, which could simulate the day/night cycle. The temperature and the humidity of the "day" period were $35^{\circ} \mathrm{C}$ and $30 \%$, respectively. For the "night" period the temperature was lowered to $21^{\circ} \mathrm{C}$ and the humidity was raised to $50 \%$. Hydrated GCL specimens were put in two containers and covered with $203.2 \mathrm{~mm}$ and $457.2 \mathrm{~mm}$ of sand, respectively. After the 90 days of testing, the final water contents of GCL specimens were as high as $260 \%$ and $248 \%$, respectively.

However, results of tests performed by Yao (1998) did not show hydrated GCLs have a strong ability to retain water. GCL specimens were placed under $0.5 \mathrm{~m}$ of moist sand and loosely compacted moist clay in two 86 liter buckets. The GCL specimens were allowed to absorb water under dead weights that imposed a vertical stress that is equivalent to $0.5 \mathrm{~m}$ of soil before they were put in the buckets. The test was performed over a 90-day period spanning from March 1998 to May 1998. The monthly average temperatures were $17.2^{\circ} \mathrm{C}, 21.1^{\circ} \mathrm{C}$, and $24.6^{\circ} \mathrm{C}$. The average humidity during the test period was about $85 \%$. The suction in the cover soils was monitored with tensiometers. The variations of the water content of GCL specimens with time are shown in Fig. 1. The results are also listed in Table 1 . The final water contents of the specimens are comparable to the results of absorption tests performed by Daniel et al. (1993).

In addition, the result of large bench scale tests that was intended to simulate field conditions in arid regions showed that the GCL sample tested severely cracked

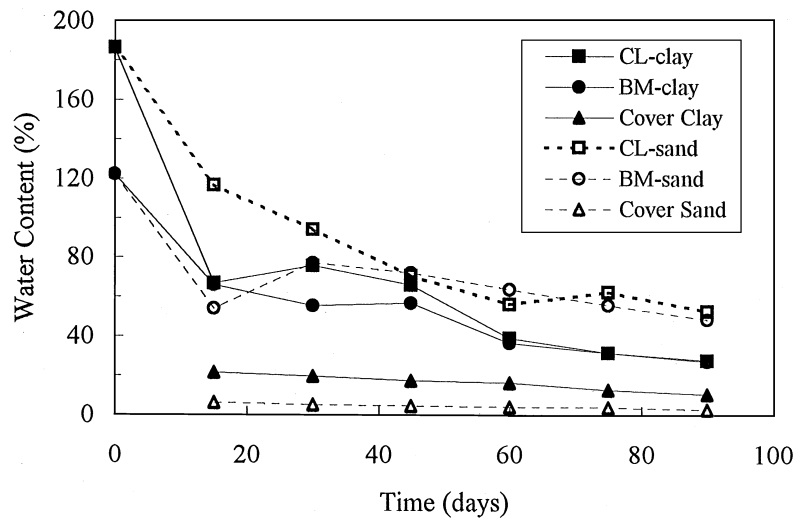

Fig. 1. Variation of water content of GCL specimens with time (Yao, 1998). 
Table 1

Results of water retention tests of GCLs (Yao, 1998)

(a) Water content of GCL specimens placed in clay

\begin{tabular}{llllllll}
\hline Time (days) & 0 & 15 & 30 & 45 & 60 & 75 & 90 \\
\hline Claymax $^{\circledR}$ & 186.35 & 66.54 & 75.53 & 65.86 & 38.82 & 31.44 & 27.51 \\
Bentomat $^{\circledR}$ & 122.10 & 65.70 & 55.34 & 56.60 & 36.34 & 31.39 & 27.00 \\
Water content of clay (\%) & - & 21.50 & 19.49 & 17.17 & 16.10 & 12.56 & 10.30 \\
Suction in clay (mbar & 67 & 69 & 58 & 72 & 78 & 80 & 72 \\
\hline
\end{tabular}

(b) Water content of GCL specimens placed in sand

\begin{tabular}{llcccccc}
\hline Time (days) & 0 & 15 & 30 & 45 & 60 & 75 & 90 \\
\hline Claymax $^{\circledR}$ & 186.35 & 116.54 & 93.90 & 70.69 & 56.23 & 62.34 & 52.45 \\
Bentomat $^{\circledR}$ & 122.10 & 53.83 & 76.91 & 71.93 & 63.75 & 55.43 & 48.25 \\
Water content of sand \%) $^{\circledR}$ & - & 6.11 & 4.88 & 4.54 & 3.77 & 3.70 & 2.62 \\
Suction in sand (mbar) & 22 & 30 & 35 & 62 & 70 & 72 & 80 \\
\hline
\end{tabular}

when desiccated (Boardman, 1993; LaGatta et al., 1997). The pattern of cracks they described was similar to that shown in Fig. 7. The average water content of the bentonite in the dry GCL sample was 12\% (Boardman, 1993).

The most important factor that controls the gas permeability of a moist soil is the degree of saturation, which is dependent on the water content and void ratio. Since water content could vary significantly after the cover system is constructed. Therefore, it is necessary to determine the effect of various water contents on the gas permeability of GCLs.

\section{Experimental program}

\subsection{GCL materials}

The two GCLs tested in this study are Bentomat ${ }^{\circledR}$ ST and Claymax ${ }^{\circledR} 200 \mathrm{R}$, which will be designated as $\mathrm{BM}$ and $\mathrm{CL}$, respectively. $\mathrm{BM}$ is comprised of a nonwoven needlepunched geotextile that is needle punched again through a layer of bentonite into a woven slit-film geotextile. The bentonite content is $3.6 \mathrm{~kg} / \mathrm{m}^{2}$. The water content of the bentonite in dry BM is about $10-12 \%$. In CL, $3.6 \mathrm{~kg} / \mathrm{m}^{2}$ of bentonite is sandwiched between woven geotextile on the top and open weave geotextile at the bottom.

The shrinkage limits of the bentonite in the GCLs were determined according to standard test method ASTM D427-92 and are listed in Table 2. It is interesting to note that the shrinkage limits of the bentonite are very low comparing to the high water content of saturated bentonite. 
Table 2

Results of shrinkage limit tests on bentonite in the GCLs

\begin{tabular}{lll}
\hline GCL & Shrinkage limit (\%) & Volume change (\%) \\
\hline BM & 35.2 & 87.86 \\
CL & 29.9 & 88.15 \\
\hline
\end{tabular}

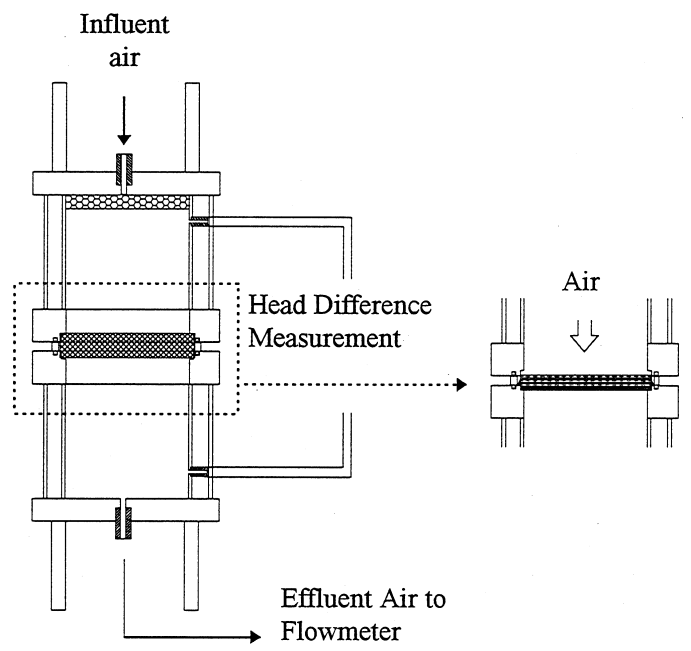

Fig. 2. Schematic diagram of the permeameter for measuring air permeability of GCL.

\subsection{Air permeability tests}

The GCL specimens were cut from the rolls supplied by the manufacturer to a diameter of $114.5 \mathrm{~mm}$. The specimen was placed in an acrylic mold with an inner diameter of $114.5 \mathrm{~mm}$. A dead load weighing $4 \mathrm{~kg}$ was put on top of specimen to provide a normal stress equivalent to that created by $300 \mathrm{~mm}$ of topsoil. The specimen was then soaked with tap water. After 1 day of hydration, the assembly was placed inside an oven and heated under a temperature of around $35^{\circ} \mathrm{C}$ for a given period of time. The specimen was then removed from the oven for air permeability testing. This process was repeated for different drying times.

The air permeameter was modified from the apparatus originally used for gradient ration test of geotextiles (Fig. 2). GCL specimens were clamped between two ringshape holders. Next, bentonite paste was placed along the edges of the specimen to prevent air leakage. The permeameter was then assembled and connected to the air permeability testing system (Fig. 3).

The flow rate of air was adjusted by regulating influent air pressure with the pressure control panel. Very low influent air pressure was used (less than $2 \mathrm{kPa}$ ). The 


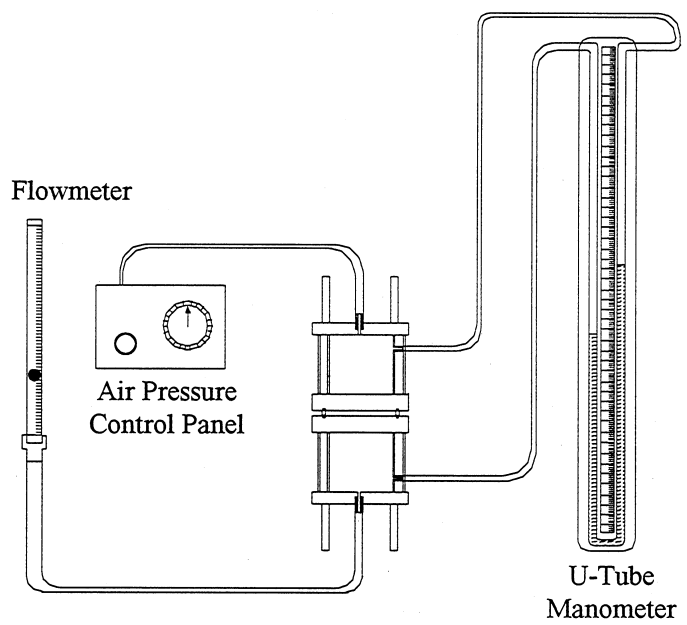

Fig. 3. Schematic diagram of the air permeability test system.

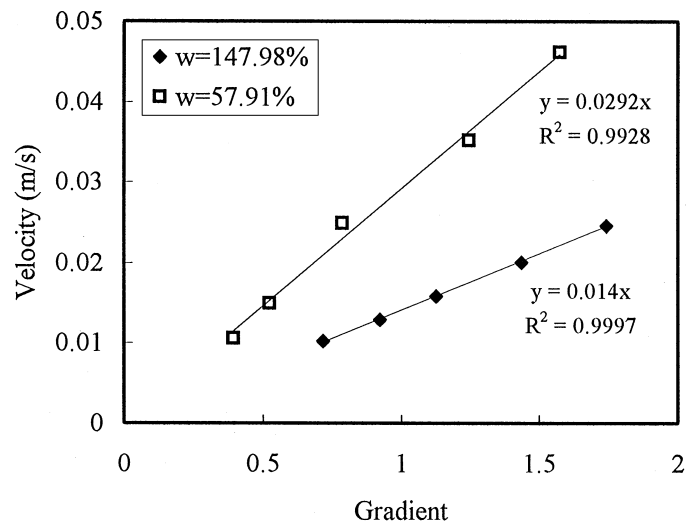

Fig. 4. Relationship between velocity and gradient for BM specimens.

range of flow rate was as high as $271 /$ min for the more permeable specimens under larger gradients and as low as $0.51 / \mathrm{min}$ for less permeable specimens under smaller gradients. The head loss across the specimen was measured by U-tube manometer. For each specimen, head difference values corresponding to 5 different flow rates were measured. It is determined that gas flow was in the laminar range. This was justified by the linear relationship between flow rate and gradient (Fig. 4). After each test, the water content and the thickness of specimen were measured.

The air permeability of the GCL specimens was computed with the following equation:

$$
k=\frac{q / A}{\left(\frac{\Delta h_{\text {total }}-\Delta h_{\text {equipment }}}{t}\right)},
$$




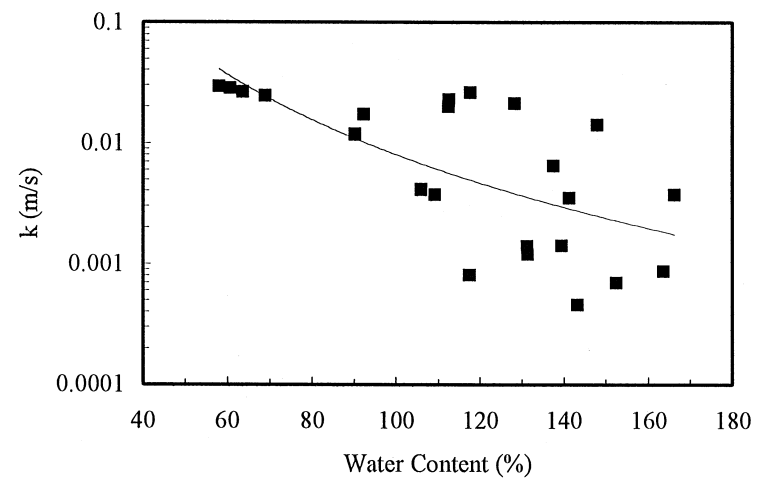

Fig. 5. Relationship between air permeability and water content for BM.

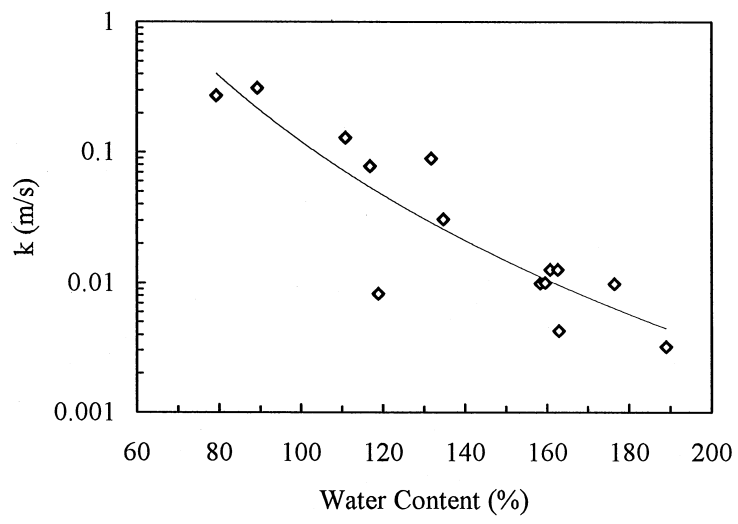

Fig. 6. Relationship between air permeability and water content for CL.

where $\Delta h_{\text {total }}$ is the total head loss measured (mm); $\Delta h_{\text {equipment }}$ is the head loss of system without any GCL specimen $(\mathrm{mm}) ; k$ is the air permeability $(\mathrm{mm} / \mathrm{s})$. The compressibility of air has been taken into account when computing the flow rates that passed through the specimens from the values measured with the flowmeter.

\section{Results and discussion}

The relationship between air permeability and water content for BM and CL is shown in Fig. 5 and Fig. 6, respectively. For CL specimens with water content higher than $190 \%$, no flow of air was observed. On the other hand, it was unable to detect any flow of air for BM specimens with water content higher than $170 \%$. It can be clearly seen that air permeability increases as the water content decreases. The relationship between air permeability and water content of CL is much clearer than for BM. 


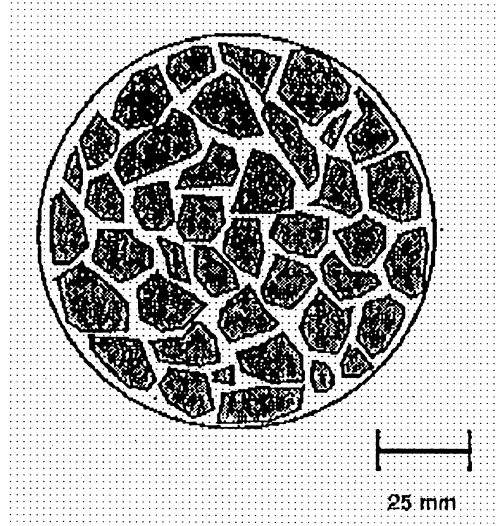

Fig. 7. Crack pattern of CL specimens.

After drying, cracks could be observed for desiccated CL specimens with water content lower than about $140 \%$. The bentonite in these specimens formed chunks of about $100 \mathrm{~mm}^{2}$ such that the GCL developed a network of wide-open cracks (Fig. 7). For CL specimens with water content higher than about $140 \%$, hairline cracks in the bentonite could be observed.

On the other hand, there was no network of large cracks found in the desiccated BM specimens. Instead of forming large chunks, the bentonite in BM specimens shrank to form small granules as when it was manufactured. The needlepunched fibers prevented the bentonite from forming chunks during the drying process. Therefore, the flow rates through the bentonite were smaller. In addition, the nonwoven geotextile in BM specimens also induced considerable head loss. In any case, the air permeability of the desiccated BM specimens was much lower than that of CL specimens.

Furthermore, the air permeability of BM specimens with water content ranging from $100 \%$ to $140 \%$ scattered considerably. This seems to be a transition zone. When the water content of the bentonite was higher than $140 \%$, the volume change of the bentonite had mainly led to a reduction in the thickness such that few pathways to air was formed. On the other hand, when the water content of bentonite reduced to below $100 \%$, the bentonite became dry enough to form granules smaller than the spacing between fibers. As a result, the air permeability increased with decreasing water content. When the water content fell within this transition zone, it was the needlepunched fibers that control the measured air permeability. It is possible that in some specimens, very small bentonite chunks formed in the places where the fibers are loose, thus the small cracks allowed air to pass through them with less resistance. However, for other specimens in which the fibers distributed uniformly, the bentonite shrank uniformly without forming small chunks and the air permeability remained very low.

The ability of GCLs to transmit air can also be expressed as the permittivity to air to allow comparison between different barrier materials. The permittivity is computed 


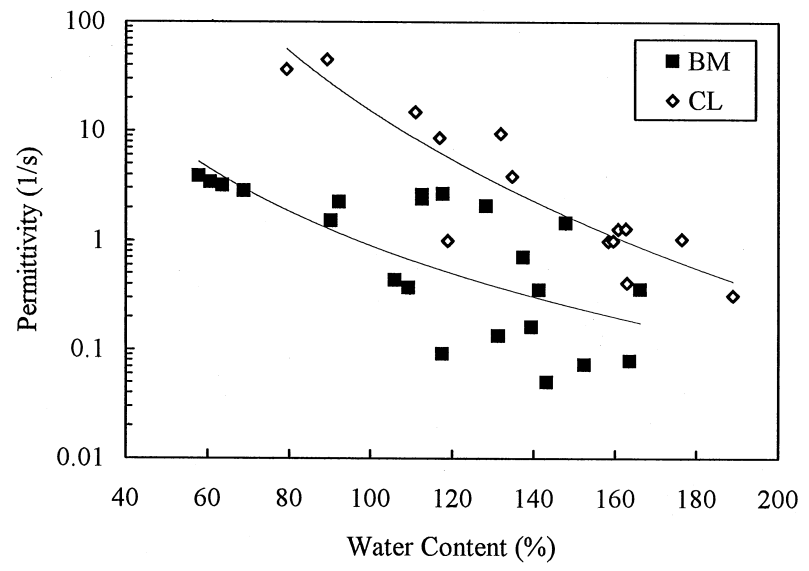

Fig. 8. Comparison of the air permittivity of BM and CL.

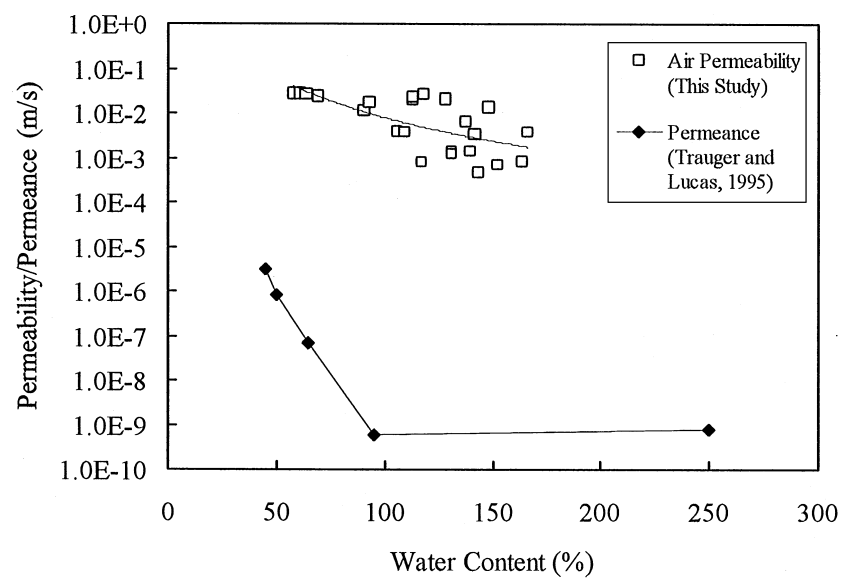

Fig. 9. Comparison between the air permeability and Permeance of BM.

with the following equation:

$$
\frac{k}{t}=\Psi=\frac{q}{\Delta h \times A} .
$$

The relationships between the air permittivity of BM and CL are shown in Fig. 8 . The air permittivity values of the desiccated $\mathrm{CL}$ are much higher than those of the desiccated $\mathrm{BM}$ for water content ranging from 50 to $150 \%$. Beyond $150 \%$, the gas permittivity of both GCLs is very low.

The air permeability of BM obtained by this study is compared with the results of gas diffusion tests performed by Trauger and Lucas (1995) in Fig. 9. The methane 
permeance through $\mathrm{BM}$ is much lower than the air permeability obtained by this study. The permeance was computed from the results of diffusion of methane though BM specimens. Advection of gas was not allowed in diffusion tests. Otherwise, methane would have passed through the drier BM specimens at a much faster rate.

Both advection and diffusion should be taken into account when estimating the gas flux through the GCLs in a landfill cover system. For desiccated GCLs with lower water contents, advection dominates the gas transport. For GCLs with high water contents, only a very small amount of gas would diffuse through the material. It is important to maintain the GCLs in a near saturation state in order to limit the gas migration. However, the results of water absorption tests by Daniel et al. (1993) and water retention tests by Yao (1998) indicate that GCLs will not maintain fully hydrated when they are in contact with soils. Therefore, GCLs are not as good in limiting gas emission out from the landfills as they are in preventing water infiltration into the landfills.

\section{Conclusions}

The air permeability of two types of GCLs was measured in this study. The results showed that it is difficult for air to pass through fully hydrated GCL specimens. However, when desiccated, the bentonite in the GCLs experienced significant volume change and developed cracks that acted as the pathway for rapid transmission of gas. The air permeability of the GCL specimens started to increase even when the water contents were still considerably high.

The existence of needlepunched fibers has a significant influence on the cracking pattern and the air permeability of the GCL. As a result, the air permeability of the $\mathrm{BM}$ specimens, which have thicker geotextiles and needlepunched fibers, is lower than that of the CL specimens.

The geosynthetic clay liners have been proven to be superior hydraulic barriers. They are gaining popularity for their many advantages over compacted soils. However, the air permeability of desiccated GCLs is very high such that they are not very effective as gas barriers.

As a result, when the gas emission is not of concern, such as the cover system for landfills containing incinerated ashes or stabilized wastes, GCLs can be used as the sole hydraulic barrier materials. However, for cover systems of municipal solid waste landfills where the emission of gas has to be controlled, it is strongly recommended that the GCLs should better be used with geomembranes to form composite liners. Otherwise, considerable amount of gas would flow through the GCLs once they start to desiccate.

\section{Acknowledgements}

The authors would like to thank Mr. Robert Trauger of CETCO for providing the GCL samples and related product information. 


\section{References}

Boardman, B.T., 1993. The potential use of geosynthetic clay liners as final covers in arid regions. MS Thesis, University of Texas, Austin, Texas, USA.

Daniel, D.E., 1991. Clay liners and covers for waste disposal facilities, unpublished short course class Notes, University of Texas at Austin, Austin, Texas, USA.

Daniel, D.E., Scranton, H.B., 1996. Report of 1995 Workshop on Geosynthetic Clay Liners, EPA/600/R96/149, U.S. EPA, Cincinnati, OH, USA, 228p.

Daniel, D.E., Shan, H.-Y., Anderson, J., 1993. Effects of Partial Wetting on Strength and Hydrocarbon Permeability of a Geosynthetic Clay Liner. In: Proceedings Geosynthetics 93. Vancouver, British Columbia, Canada, pp. 1483-1496.

Figueroa, R.A., Stegmann, R., 1991. Gas migration through natural liners. Proceedings, Sardinia '91, 3rd International Landfill Symposium, S. Margherita di Pula, Cagliari, Italy, pp. 167-177.

Geoservices, Inc., 1989. Report of moisture retention tests, Claymax CR. Report to James Clem Corp., Norcross, Georgia, 14p.

Koerner, R.M., Daniel, D.E., 1997. Final covers for solid waste landfills and abandoned dumps. ASCE, $256 \mathrm{p}$.

LaGatta, M.D., Boardman, B.T., Cooley, B.H., Daniel, D.E., 1997. Geosynthetic clay liners subjected to differential settlement. Journal of Geotechnical and Geoenvironmental Engng., ASCE 123 (5), 402-410.

Trauger, R.J., Lucas, H.L., 1995. Determining the flow rate of landfill gas constituents through a geosynthetic clay liner. In: Proceedings Geosynthetics '95. Nashville, Tennessee, USA, pp. 1085-1096.

Yao, J.-T., 1998. Air permeability of landfill cover barrier Layer. MS Thesis, National Chiao Tung University, Taiwan, 51p (in Chinese). 